\title{
Relationships within aphids Cinara (Cupressobium) (Hemiptera) based on mitochondrial and nuclear DNA sequences
}

\author{
Roma Durak • Dorota Lachowska-Cierlik • \\ Slawomir Bartoszewski
}

Received: 31 May 2013 /Revised: 24 September 2013 / Accepted: 7 November 2013 /Published online: 28 November 2013

(C) The Author(s) 2013. This article is published with open access at Springerlink.com

\begin{abstract}
The relationships between Cinara (Cupressobium) aphids inhabiting woody parts and leaves of conifers belonging to Cupressaceae have been studied using a mitochondrial gene $(\mathrm{COI})$ and a nuclear gene $(\mathrm{EF} 1-\alpha)$. Based on the COI sequences, genetic distances between species ranged from $5.6 \%$ between Cinara (C.) tujafilina (del Guercio) and Cinara (C.) juniperi (De Geer) to $10.5 \%$ between $C$. (C.) tujafilina and Cinara (C.) mordvilkoi (Pašek). Genetic distances among EF1- $\alpha$ sequences were lower and showed from $0.1 \%$ between $C$. cupressi and $C$. juniperi to $2.3 \%$ between C. tujafilina and C. mordvilkoi. Molecular phylogenetic trees were constructed using the Bayesian inference (BI) phylogenetic analysis and maximum parsimony (MP) criterion. Phylogenetic trees obtained based on COI and EF1- $\alpha$ marker genes created two sister clades. Our results indicate that Cinara (Cupressobium) are a monophyletic group of aphids. Phylogenetic relationships amongst Cupressobium aphids do not result from the association with the host plant, but from the feeding site on the host plant or an ability to change the microhabitat on the plant. As closely related species inhabit similar microhabitats on different host plants, it suggests that the host switching is the main mode of speciation in this subgenus.
\end{abstract}

R. Durak $(\bowtie)$

Department of Invertebrate Zoology, University of Rzeszow,

Zelwerowicza 4, 35-601 Rzeszów, Poland

e-mail: rdurak@univ.rzeszow.pl

D. Lachowska-Cierlik

Department of Entomology, Institute of Zoology, Jagiellonian

University, Gronostajowa 9, 30-387 Kraków, Poland

S. Bartoszewski

Department of Biochemistry and Cell Biology, University

of Rzeszow, Zelwerowicza 4, 35-601 Rzeszów, Poland
Keywords Cinara (Cupressobium) · Cytochrome oxidase I · Ecology $\cdot$ Elongation factor $1-\alpha \cdot$ Phylogeny

\section{Introduction}

Aphids belonging to Cinara (Hemiptera, Sternorrhyncha, Lachnidae) most often infest woody parts and leaves of Pinaceae and Cupressaceae (Eastop 1972; Blackman, Eastop 1994). The species have simple development cycle (they are monoecious), which enables all generations to develop on one species of host plant. Most of those insect species, classified in Cinara subgenus (Cinara) are associated with Pinaceae (Blackman, Eastop 1994), a plant family occurring mainly in cool and moderate climates of the northern hemisphere. The host plant species infested by Cinara (Cinara) consist of the following genera: Picea A. Dietr., Pinus L., Larix Mill, Pseudotsuga Carriere, Abies Mill., Cedrus Belon ex Trew, Pseudolarix and Tsuga Carriere. The cypress family (Cupressaceae) includes nearly 150 species in 30 genera, occurring mainly in warm climate, e.g., Juniperus L., Thuja L., Chamaecyparis L., Cupressus L., Thujopsis L.f., Platycladeus L., Microbiota Kom. genera. These plant genera are infested by aphids from Cinara (Cupressobium) subgenus (Blackman, Eastop 1994). They can be classified into subgenera according to the following morphological features: the length of dorsal HT I (first segment of the hind tarsus) and the number of subapical hairs on processus terminalis (PT) (Blackman, Eastop 1994).

An interesting phenomenon among Cinara infesting the Pinaceae family is the fact that many aphid species can be associated with one plant species. Blackman, Eastop (1994) report that over 100 Cinara species are associated with Pinus 
$s p$. As many as 14 Cinara species are trophically associated with $P$. edulis Engelm, while five species are associated with P. monophylla Torr., Frem (Voegtlin, Bridges 1988; Favret, Voegtlin 2004). The Cinara related to Cupressaceae are a different case, as one aphid species can infest plants belonging to various genera or can be monophagous and associated with one plant species only, while the plant species is also infested by a small number of other Cinara species. Blackman, Eastop (1994) report 20 Cinara infesting the Cupressaceae family. As all Cinara species are very similar, morphological data are not sufficient for adequate phylogenetic analysis (Foottit 1992; Watson et al. 1999).

Cinara genus was used by Normark (2000) to determine the evolution course of the Lachnidae family based on the nuclear sequence of elongation factor EF- $1 \alpha$ and cytochrome oxydase COII. Also, phylogenetic relationships between the Cinara infesting pine trees in southwestern United States based on elongation factor EF- $1 \alpha$ and cytochrome oxydase COI (Favret, Voegtlin 2004) were analyzed.

An attempt to define phylogenetic relationships between various Cinara species infesting Pinaceae indicated a closer relationship between species occupying similar feeding sites than between those infesting the same host plants (Favret, Voegtlin 2004). On the other hand, Eastop (1986) indicates clear relationships between aphid phylogenesis and their host plants. Some theories highlight the main role of host plants in the process of differentiation and speciation of insects, including aphids (Winkler, Mitter 2008; Peccoud et al. 2010). Due to problems with in-situ monitoring in spite of their large size when compared with other aphids, Cupressaceae-infesting Cinara are rarely used in relationship analysis in families or lower units (Ortiz-Rivas, Martinez-Torres 2010). No research on phylogenetic relations between Cupressaceae-feeding species has been conducted so far. Hence this paper aims at exploring relationships between Cinara (Cupressobium) species infesting Cupressaceae and defining whether Cinara (Cupressobium) are associated closer with a plant species or with their feeding site or microhabitat, determining the type of speciation of these aphids: cospeciation with host plant or by host shifts.

\section{Materials and methods}

Taxon sampling

Specimens of Cinara (Cupressobium) cupressi (Buckton), Cinara (C.) juniperi (De Geer), Cinara (C.) mordvilkoi (Pašek), Cinara (C.) fresai (Blanchard) and Cinara (C.) tujafilina (del Guercio) species were collected from 2007 to 2009 from Juniperus communis, J. scopulorum, Thuja occidentalis and T. orientalis (Platycladus orientalis) in Poland. They were then preserved in $99.8 \%$ ethanol and stored at $-20{ }^{\circ} \mathrm{C}$ at the University of Rzeszow, Department of Invertebrate Zoology, Rzeszow, Poland. The COI and EF1- $\alpha$ sequences of $C$. cupressi, C. juniperi, C. mordvilkoi, and $C$. fresai species obtained during this study were deposited in GenBank (Table 1). We also used COI and EF1- $\alpha$ sequences available from GenBank for Cinara (Cinara) and Rhopalosiphum padi (Linnaeus) and Acyrthosiphon pisum (Harris), belonging to Aphididae as outgroups. All aphid species covered in this study are presented in Table 1, with annotations pertaining to the origin of sequences (this study or GenBank) and GenBank accession number. All voucher specimens are preserved in the Department of Invertebrate Zoology, University of Rzeszow, Poland.

DNA extraction, polymerase chain reaction amplification and sequencing

Phylogenies were derived using data from DNA fragments of genes, namely partial COI and partial EF1- $\alpha$. The DNA was extracted from a single aphid with a standard phenolchloroform procedure. The DNA was then PCR-amplified with LCO1490/HCO2198 primers (Folmer et al. 1994), which give about 400-650 bp of the COI gene from the mitochondrial genome. The EF1- $\alpha$ of 760-770 bp was amplified with primers EF3 and EF6 (von Dohlen et al. 2002) and a newly designed primer pair EF3b (5' GTGAAATCGGCAGCAC CCT 3') and EF6b (5' CACAGAGATTTCATCAAGAACA TGAT 3').

PCR reactions were carried out in $50 \mu$ reactions containing $1 \mu \mathrm{l}$ DNA $(0.4 \mathrm{ng} / \mathrm{ml}), 1.5 \mu \mathrm{l}$ of each primer $(10 \mathrm{pM})$, $0.5 \mu \mathrm{l}$ of Taq DNA polymerase $(5 \mathrm{U} / \mu \mathrm{l}), 5 \mu \mathrm{l}$ of buffer 3 (Expand Long Template PCR System, Roche), $1 \mu \mathrm{l}$ of $10 \mathrm{mM}$ dNTPs and ultra-pure water. The temperature profile for the amplification of the COI gene fragment included an initial denaturation step at $95{ }^{\circ} \mathrm{C}$ for 2 min followed by three cycles at $95{ }^{\circ} \mathrm{C}$ for $30 \mathrm{~s}, 47^{\circ} \mathrm{C}$ for $30 \mathrm{~s}, 72{ }^{\circ} \mathrm{C}$ for $1 \mathrm{~min} 10 \mathrm{~s}$ and 32 cycles at $95^{\circ} \mathrm{C}$ for $30 \mathrm{~s}, 51-53{ }^{\circ} \mathrm{C}$ for $30 \mathrm{~s}$ (depending on primer set), $72{ }^{\circ} \mathrm{C}$ for $1 \mathrm{~min} 10 \mathrm{~s}$ and a final extension period at $72{ }^{\circ} \mathrm{C}$ for $10 \mathrm{~min}$. Amplification products were resolved by electrophoresis in $2 \%$ agarose gels. PCR products were cleaned with High Pure PCR Product Purification Kit (Roche) and then sequenced at Genomed service (www.genomed.pl).

Sequence analysis and phylogenetic reconstructions

Sequences were checked and aligned using BioEdit v.7.0.5.2 (Hall 1999) and ClustalX (Thompson et al. 1997). All alignments were visually verified and manually edited. The sequences were also verified for protein-coding frame-shifts using Mega 4.0. in order to avoid pseudogenes (Tamura et al. 2007) and compared with sequences from GenBank with a Blast search. The Akaike Information Criterion in MrModeltest 
Table 1 Aphid species analyzed, classified following Heie and Wegierek (2009), host and GenBank accession numbers of COI, EF1- $\alpha$ gene fragments obtained in this study and those that were already available through GenBank

\begin{tabular}{|c|c|c|c|c|c|}
\hline \multirow[t]{2}{*}{ Tribe } & \multirow[t]{2}{*}{ Species } & \multirow[t]{2}{*}{ Host plants } & \multirow[t]{2}{*}{ Feeding site ${ }^{a}$} & \multicolumn{2}{|c|}{ GenBank acc. no. } \\
\hline & & & & $\mathrm{COI}$ & EF1- $\alpha$ \\
\hline \multirow[t]{24}{*}{ Cinarini } & Cinara cupressi & Thuja occidentalis & branch, trunk & JQ247997 & JQ248000 \\
\hline & Cinara fresai & Juniperus scopulorum & branch, trunk & JQ247996 & JQ247998 \\
\hline & Cinara juniperi & Juniperus communis & branch, needle & JN190924 ${ }^{8}$ & JQ247999 \\
\hline & Cinara mordvilkoi & Juniperus communis & twig, root & JN190923 ${ }^{8}$ & JQ248001 \\
\hline & Cinara tujafilina & Thuja orientalis & twig, root & EU151496 ${ }^{9}$ & FM174684 \\
\hline & Cinara anelia & Pinus sp. & & EU701607 $7^{1}$ & \\
\hline & Cinara atlantica & Pinus sp. & & EU701608 ${ }^{1}$ & \\
\hline & Cinara cedri & Cedrus sp. & & & FM174683 \\
\hline & Cinara coloradensis & Picea sp. & & EU701613 ${ }^{1}$ & \\
\hline & Cinara edulis & Pinus edulis & & & AY472023 ${ }^{6}$ \\
\hline & Cinara formosana & Pinus sp. & & GU978790² & \\
\hline & Cinara glabra & Pinus ponderosa & & & AF $163870^{5}$ \\
\hline & Cinara laricis & Larix sp. & & JX034917 & \\
\hline & Cinara longipennis & Abies holophylla & & & GU457845 \\
\hline & Cinara occidentalis & Abies $s p$. & & EU701619 ${ }^{1}$ & \\
\hline & Cinara pergandei & Pinus sp. & & EU70162 $1^{1}$ & \\
\hline & Cinara picea & Picea sp. & & JQ916814³ & \\
\hline & Cinara pinea & Pinus sylvestris & & JQ916782 3 & AF $163871^{5}$ \\
\hline & Cinara ponderosae & Pinus ponderosa & & & AF $163872^{5}$ \\
\hline & Cinara shinji & Pinus sp. & & GU978787² & \\
\hline & Cinara strobi & Pinus strobus & & & AY472033 \\
\hline & Cinara terminalis & Pinus monophylla & & & AY472035 \\
\hline & Cinara wahtolca & Pinus edulis & & & AY472037 \\
\hline & Cinara watsoni & Pinus sp. & & EU701624 ${ }^{1}$ & \\
\hline Aphidini & Acyrthosiphon pisum & & & EU701283 $^{1}$ & FM174698 \\
\hline Rhopalosiphini & Rhopalosiphum padi & & & EU701893 $^{1}$ & FM174699 \\
\hline
\end{tabular}

Numbers indicate sequences from previous studies: ${ }^{1}$ Foottit et al. (2008), ${ }^{2}$ Lee et al. (2011), ${ }^{3}$ Chen et al.. (2012), ${ }^{4}$ Ortiz-Rivas \& Martínez-Torres (2010), ${ }^{5}$ Normark (2000), ${ }^{6}$ Favret, Voegthlin (2004), ${ }^{7}$ Kim et al. (2011), ${ }^{8}$ Durak (2011), ${ }^{9}$ Durak et al. (2008).

${ }^{\mathrm{a}}$ based on Blackman and Eastop and our own observations; twig=0.5-2 cm diameter, branch=2-8 cm diameter.

2.3 (Nylander 2004) in conjunction with PAUP* (Swofford 2002) were used to determine the best-fitting nucleotide substitution model. The GTR $+\mathrm{I}+\mathrm{G}$ model was chosen for $\mathrm{COI}$ and the GTR $+\mathrm{G}$ model for EF1- $\alpha$ (Hasegawa et al. 1985). Two methods for phylogeny reconstruction were used - Bayesian inference (BI) and maximum parsimony (MP). BI was run using MrBayes 3.1 (Huelsenbeck, Ronquist 2001; Huelsenbeck et al. 2001) with one cold and three heated Markov chains for 3,000,000 generations and trees were sampled every 100th generation (according to Hall 2007). Each simulation was run twice. Convergence of Bayesian analyses was estimated using Tracer v. 1.5.0 (Rambaut, Drummond 2003-2009) and appropriate number of sampled trees were discarded as 'burn-in', and the remainder used to reconstruct a $50 \%$ majority rule consensus tree. MP was computed using PAUP* 4.0b10. For all MP analyses, heuristic search with tree bisection-reconnection (TBR) branch swapping and random addition sequences, MaxTrees $=500$ were conducted with 500 random addition replicates. Gaps were treated as fifth character state. Node support was assessed with the bootstrap technique using 5000 pseudoreplicates and TBR branch swapping. Tree reconstruction was performed separately for each marker and afterward on combined sequences. All trees were generated with TreeView 1.6.6 (Page 1996).

\section{Results}

Sequence analysis

No polymorphism in COI and EF1- $\alpha$ sequences was detected in specimens belonging to particular species, indicating that 
COI barcode and EF1- $\alpha$ identities were congruent with morphological species concept. Therefore a single sequence was chosen to represent each species in analyses. COI amplification resulted in a $444 \mathrm{bp}$ product for each aphid species. As in other insects, all COI sequences were abundant in AT. EF-1- $\alpha$ primers generated $760-770$ bp products which were then sequenced.

The polymorphism rate of mitochondrial genes was approx. $24 \%$ variable sites and about $14 \%$ parsimony-informative sites. Sequences of EF1- $\alpha$ fragments were slightly more variable (about $32 \%$ variable sites and $21 \%$ parsimonyinformative sites).

\section{Phylogenetic analysis}

MP heuristic searches for COI sequences resulted in one cladeogram (length $=329$, consistency index $(\mathrm{CI})=0.5471$, retention index $(\mathrm{RI})=0.5300)$, based on 65 parsimony informative characters. MP heuristic searches for EF1- $\alpha$ sequences resulted in one cladeogram (length $=488$, consistency index $(\mathrm{CI})=0.7807$, retention index $(\mathrm{RI})=0.8431)$, based on 172 parsimony informative characters. The GTR $+\mathrm{I}+\mathrm{G}$ model was chosen for COI (proportion of invariable sites $\mathrm{I}=0.5531$; gamma distribution shape parameter $\mathrm{G}=0.6594$ ) and the $\mathrm{GTR}+\mathrm{G}$ model for EF1- $\alpha$ (proportion of invariable sites $\mathrm{I}=0$; gamma distribution shape parameter $G=0.2270$ ), as the best nucleotide substitution model for analyses and pairwise distance calculations. The MP and Bayesian analyses resulted in a congruent topology, so only Bayesian trees are shown in Figs. 1 and 2 (with Bayesian posterior probabilities, PP and MP bootstrap values).

COI barcode genetic distances between species ranged from $5.6 \%$ between $C$. tujafilina and $C$. juniperi to $10.5 \%$ between $C$. tujafilina and C. mordvilkoi (Table 2). Mitochondrial distance between species of Cupressobium and those of outgroup species was $13.5-17.4 \%$. The COI proved to be a good barcoding marker as only a $5 \%$ minimum barcoding gap was found within and between species.

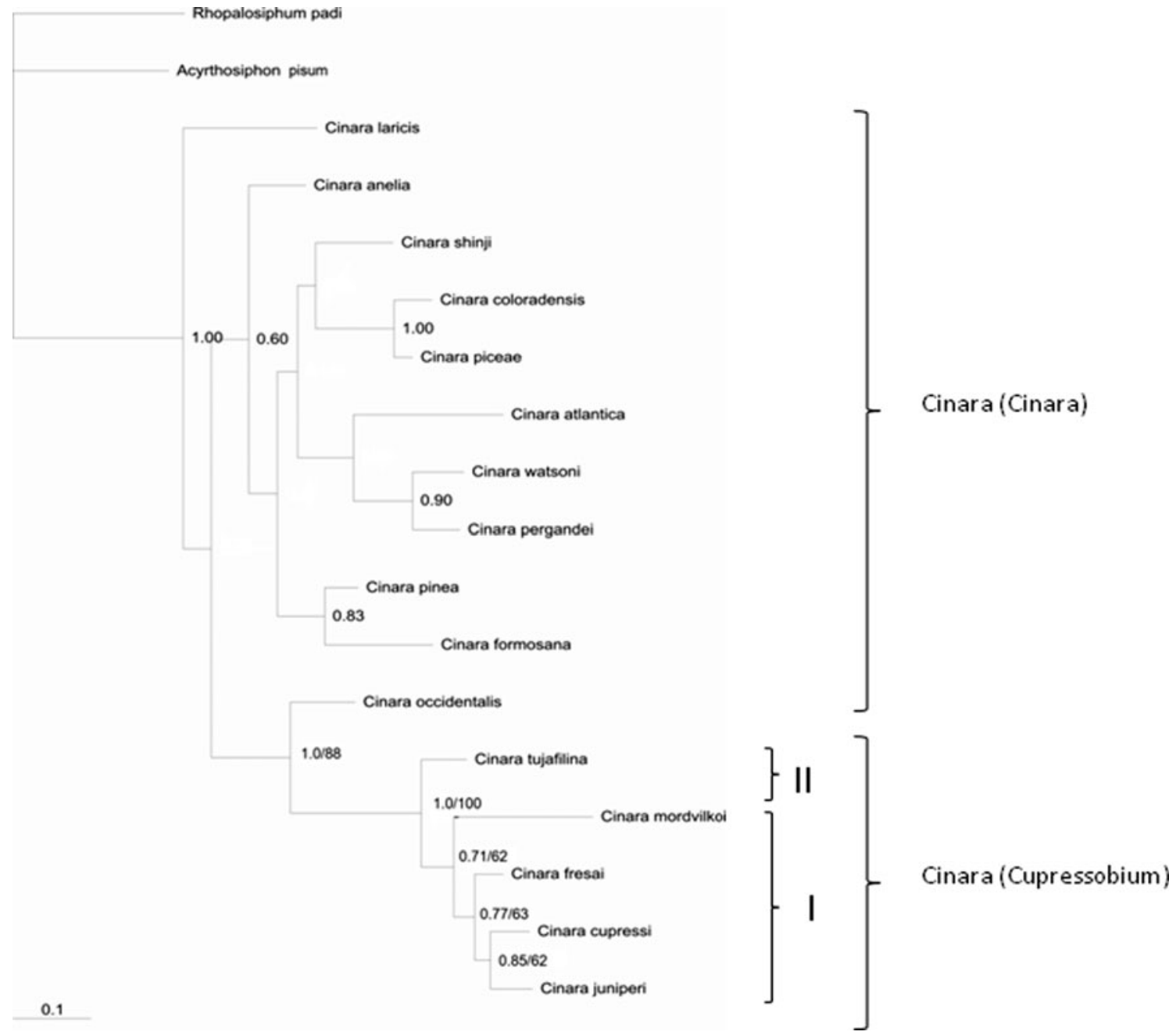

Fig. 1 Bayesian tree constructed for COI of Cinara (Cupressobium). Posterior probabilities of Bayesian inferences/bootstrap values for maximum parsimony are presented on tree branches 


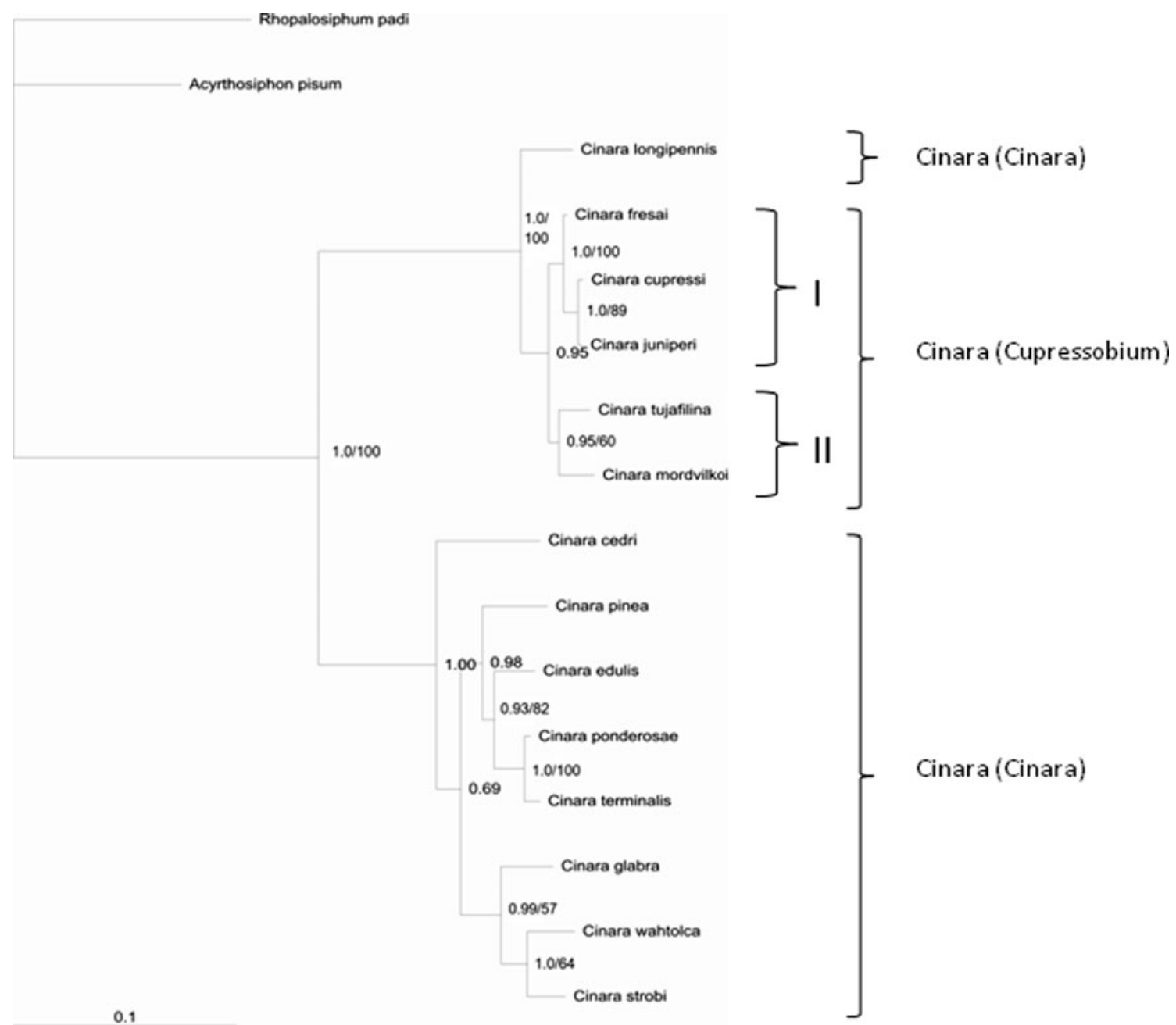

Fig. 2 Bayesian tree constructed for EF1- $\alpha$ of Cinara (Cupressobium). Posterior probabilities of Bayesian inferences/bootstrap values for maximum parsimony are presented on tree branches

Genetic distances among EF1- $\alpha$ sequences were lower and amounted to $0.1 \%$ between $C$. cupressi and $C$. juniperi and to $2.3 \%$ between C. tujafilina and C. mordvilkoi. The genetic distance was $2.1 \%$ between $C$. cupressi and $C$. tujafilina; $2.1 \%$ between $C$. cupressi and $C$. mordvilkoi; $0.3 \%$ between C. cupressi and $C$. fresai; $2.0 \%$ between $C$. juniperi and $C$. tujafilina; $2.1 \%$ between $C$. juniperi and C. mordvilkoi; $0.2 \%$ between $C$. juniperi and $C$. fresai; $1.7 \%$ between $C$. tujafilina and $C$. fresai. The genetic distance between species belonging to Cupressobium and those of outgroup species was $15.6-18.7 \%$ (Table 3).

GenBank sequences available for Cinara (Cinara) subgenus were also included in phylogenetic tree construction (Table 1). Both phylogenetic trees indicate that Cinara subgenus Cupressobium form a monophyletic clade sister to Cinara (Cinara) (1.0 PP, 88 \% bootstrap; 1.0 PP, $100 \%$ bootstrap) (Figs. 1, 2).

The tree based on the mtDNA forms two main clades. Group one (I) includes two well-supported subclades, one containing C. cupressi, C. juniperi ( $0.85 \mathrm{PP}, 62 \%$ bootstrap value) and $C$. fresai ( $0.77 \mathrm{PP}, 63 \%$ bootstrap value) and the other one including C. mordvilkoi ( $0.71 \mathrm{PP}, 62 \%$ bootstrap value). C. tujafilina creates the most external clade (II), sister to group one (I) (1.0 PP, $100 \%$ bootstrap value) (Fig. 1).

The topology of the tree obtained on the basis of EF1- $\alpha$ sequences was similar but showed a closer relationship of $C$. tujafilina with C. mordvilkoi. Group one (I) combined $C$. cupressi and $C$. juniperi (1.00 PP, $89 \%$ bootstrap value) and $C$. fresai (1.00 PP, $100 \%$ bootstrap value). Clade two (II) was also well supported and apart from $C$. tujafilina it also included C. mordvilkoi (0.95 PP, $60 \%$ bootstrap) (Fig. 2).

All analyses performed indicate that Cinara (Cupressobium), associated with various Cupressaceae plants, do not form host plant-based clades. However, it was proven that clades encompassed species from the same microhabitat, i.e., the plant part. Both nuclear and mitochondrial data strongly support a clade formed of aphid species infesting above-ground parts of plant, e.g., branches, trunks, and young shoots of various Juniperus sp. and Thuja sp. (C. fresai, C. cupressi, C. juniperi). 
Table 2 Mitochondrial DNA pairwise distances for all pairs of aphid species studied

\begin{tabular}{|c|c|c|c|c|c|c|c|c|c|c|c|c|c|c|c|c|c|c|c|}
\hline & Species & 1 & 2 & 3 & 4 & 5 & 6 & 7 & 8 & 9 & 10 & 11 & 12 & 13 & 14 & 15 & 16 & 17 & 18 \\
\hline 1 & Cinara cupressi & & & & & & & & & & & & & & & & & & \\
\hline 2 & Cinara fresai & 6.1 & & & & & & & & & & & & & & & & & \\
\hline 3 & Cinara juniperi & 8.1 & 6.5 & & & & & & & & & & & & & & & & \\
\hline 4 & Cinara mordvilkoi & 10.0 & 10.0 & 9.5 & & & & & & & & & & & & & & & \\
\hline 5 & Cinara tujafilina & 6.2 & 6.5 & 5.6 & 10.5 & & & & & & & & & & & & & & \\
\hline 6 & Cinara anelia & 10.6 & 10.6 & 9.7 & 12.0 & 10.9 & & & & & & & & & & & & & \\
\hline 7 & Cinara atlantica & 13.5 & 12.4 & 11.2 & 14.9 & 11.8 & 7.9 & & & & & & & & & & & & \\
\hline 8 & Cinara coloradensis & 10.9 & 12.5 & 10.2 & 14.4 & 12.0 & 7.8 & 9.1 & & & & & & & & & & & \\
\hline 9 & Cinara formosana & 11.3 & 11.5 & 9.9 & 13.9 & 11.0 & 8.3 & 8.7 & 9.8 & & & & & & & & & & \\
\hline 10 & Cinara laricis & 11.5 & 10.9 & 10.0 & 13.5 & 11.0 & 7.0 & 9.7 & 9.4 & 9.3 & & & & & & & & & \\
\hline 11 & Cinara occidentalis & 10.6 & 8.5 & 7.2 & 10.9 & 9.6 & 7.4 & 9.6 & 9.4 & 9.2 & 7.5 & & & & & & & & \\
\hline 12 & Cinara pergandei & 10.9 & 10.2 & 9.4 & 12.3 & 10.2 & 6.7 & 6.5 & 7.4 & 8.0 & 8.1 & 7.6 & & & & & & & \\
\hline 13 & Cinara picea & 10.5 & 10.2 & 9.5 & 14.9 & 11.2 & 6.8 & 8.6 & 3.3 & 8.8 & 8.8 & 9.1 & 6.5 & & & & & & \\
\hline 14 & Cinara pinea & 12.7 & 12.9 & 10.3 & 14.1 & 13.1 & 7.1 & 9.2 & 8.3 & 7.1 & 8.7 & 9.0 & 6.6 & 7.5 & & & & & \\
\hline 15 & Cinara shinji & 12.3 & 11.8 & 11.4 & 15.5 & 13.0 & 8.1 & 9.2 & 8.6 & 8.7 & 10.0 & 9.2 & 6.7 & 7.1 & 8.2 & & & & \\
\hline 16 & Cinara watsoni & 11.7 & 12.2 & 10.4 & 12.7 & 11.3 & 6.9 & 8.1 & 7.1 & 8.8 & 9.3 & 8.4 & 4.1 & 6.8 & 7.7 & 6.8 & & & \\
\hline 17 & Acyrthosiphon pisum & 13.7 & 14.8 & 13.8 & 17.4 & 14.7 & 10.9 & 11.1 & 11.4 & 12.6 & 12.3 & 11.2 & 9.6 & 10.8 & 11.3 & 12.3 & 9.8 & & \\
\hline 18 & Rhopalosiphum padi & 13.7 & 13.5 & 13.8 & 16.5 & 14.7 & 11.4 & 11.3 & 14.1 & 12.0 & 10.8 & 11.9 & 10.7 & 12.1 & 13.0 & 13.3 & 11.6 & 10.1 & \\
\hline
\end{tabular}

The formation of a clade including $C$. tujafilina is very interesting. This clade is very well supported by both nuclear and mitochondrial data analyses. Nuclear data also indicates the strongest similarity between $C$. mordvilkoi and C. tujafilina. This is interesting due to the fact that those species do not have common habitat on the host plant, but they change habitats depending on environmental factors. Both species infest lignified plant parts or roots and underground plant parts.

\section{Discussion}

All Cinara (Cupressobium) species are closely related, as proven by the genetic distance between them, which fluctuated from 5 to $10 \%$ for COI and from 0.1 to $2.3 \%$ for EF $1-\alpha$ (Table 2, Table 3). Values obtained also enable precise species classification, considering the value of $2 \%$ to be sufficient to separate closely related species with mtDNA (Stern et al.

Table 3 Pairwise distances for nuclear DNA sequences from all pairs of aphid species studied

\begin{tabular}{|c|c|c|c|c|c|c|c|c|c|c|c|c|c|c|c|c|c|}
\hline & Species & 1 & 2 & 3 & 4 & 5 & 6 & 7 & 8 & 9 & 10 & 11 & 12 & 13 & 14 & 15 & 16 \\
\hline 1 & Cinara cupressi & & & & & & & & & & & & & & & & \\
\hline 2 & Cinara fresai & 0.3 & & & & & & & & & & & & & & & \\
\hline 3 & Cinara juniperi & 0.1 & 0.2 & & & & & & & & & & & & & & \\
\hline 4 & Cinara mordvilkoi & 2.1 & 2.0 & 2.1 & & & & & & & & & & & & & \\
\hline 5 & Cinara tujafilina & 2.1 & 1.7 & 2.0 & 2.3 & & & & & & & & & & & & \\
\hline 6 & Cinara longipennis & 3.2 & 2.8 & 3.1 & 4.0 & 3.7 & & & & & & & & & & & \\
\hline 7 & Cinara ponderosae & 12.2 & 11.8 & 12.1 & 12.9 & 12.8 & 12.1 & & & & & & & & & & \\
\hline 8 & Cinara terminalis & 12.3 & 11.9 & 12.2 & 12.9 & 12.8 & 12.2 & 0.6 & & & & & & & & & \\
\hline 9 & Cinara pinea & 14.7 & 14.1 & 14.5 & 15.3 & 15.8 & 14.1 & 4.2 & 4.4 & & & & & & & & \\
\hline 10 & Cinara edulis & 12.2 & 11.7 & 12.0 & 12.7 & 12.5 & 12.2 & 2.5 & 3.0 & 4.7 & & & & & & & \\
\hline 11 & Cinara wahtolca & 11.9 & 11.6 & 11.9 & 12.8 & 12.3 & 12.1 & 6.0 & 6.4 & 8.2 & 5.9 & & & & & & \\
\hline 12 & Cinara strobi & 12.8 & 12.5 & 12.8 & 13.4 & 13.0 & 12.9 & 5.4 & 5.1 & 6.7 & 5.4 & 3.0 & & & & & \\
\hline 13 & Cinara glabra & 11.6 & 11.2 & 11.6 & 12.5 & 12.0 & 12.2 & 5.1 & 5.5 & 6.8 & 5.3 & 4.1 & 4.4 & & & & \\
\hline 14 & Cinara cedri & 13.0 & 12.7 & 13.0 & 13.8 & 13.4 & 12.6 & 5.9 & 5.9 & 7.5 & 6.7 & 7.9 & 7.1 & 7.2 & & & \\
\hline 15 & Acyrthosiphon pisum & 15.9 & 16.1 & 15.7 & 15.6 & 16.2 & 16.5 & 17.2 & 17.6 & 19.8 & 17.0 & 16.8 & 18.0 & 17.4 & 16.8 & & \\
\hline 16 & Rhopalosiphum padi & 18.4 & 18.3 & 18.5 & 18.1 & 18.7 & 19.0 & 18.3 & 18.8 & 20.5 & 18.4 & 17.8 & 19.1 & 18.7 & 17.9 & 11.6 & \\
\hline
\end{tabular}


1997). The obtained range of genetic distances is slightly higher than for Cinara (Cinara) representatives associated with Pinus sp. (Favret, Voegtlin 2004) and similar to that observed between representatives of Uroleucon subgenera (Moran et al. 1999).

Relationships between Cupressobium species determined based on COI and EF1- $\alpha$ analyses prove that $C$. (C.) cupressi, C. (C.) juniperi, and C. (C.) fresai are most closely related. They constitute a common clade, strongly supported by mitochondrial and nuclear analyses. Another clade is composed of C. (C.) tujafilina and C. (C.) mordvilkoi and is well supported by nuclear analyses. Our results for the Cinara (Cupressobium) subgenus show that EF1- $\alpha$ is an excellent marker for resolving close relationships between species. Nuclear EF1- $\alpha$ has been used for higher-level studies of insect phylogenetics. Additionally, our results show that EF1- $\alpha$ is also a good marker for resolving relationships at the species and subgenus level. This is supported by previous data indicating EF1- $\alpha$ as a good gene marker for determining phylogenetic relationships between Megoura species (Kim, Lee 2008).

The monophyletic character of Cupressobium is consistent with the earlier study by Burke et al. (2009), based on studies of symbiotic bacteria such as Buchnera and "Candidatus Serratia symbiotica" which are associated with Cinarini tribe aphids.

Our studies indicate that Cinara (Cupressobium) species do not form clades related to their host plants, however, a relationship with their microhabitat on a host plant can be observed.

It seems interesting that the highest genetic similarity is found between species that can infest lignified parts of the host plant, e.g., young shoots, branches, and trunks. Species such as $C$. cupressi and $C$. fresai are associated with many plant genera and their oligophagous features enable them to spread widely around the world, while C. juniperi is strictly monophagous and associated with Juniperus $s p$. All species, included in this group (I), infest lignified parts of host plants located above the ground.

Favret and Voegtlin (2004) found that within Cinara (Cinara) infesting various Pinus sp., a closer genetic similarity is found between species infesting similar microhabitats on plants rather than between species infesting the same species of Pinus, but localizing to different microhabitats. Cinara (Cupressobium) do not form plant-based clades and neither do Pinus-related Cinara (Cinara) (Favret, Voegtlin 2004). This indicates that the evolutionary radiation of this subgenus is not related to plant species and was made possible thanks to the ability to switch host plants. Additionally, phylogenetic relations between the studied aphid species are dissimilar to those obtained from molecular and morphological data on Cupressaceae plants (Gadek et al. 2000; Kusumi et al. 2002). The mechanism of speciation observed for Cinara (Cuppresobium) involves a host switch rather than aphidplant coevolution previously shown in Megoura sp. (Kim, Lee 2008). The host-switch evolution model is also the most frequently cited speciation model for other aphid species (Moran et al. 1999; Guldemond 1990; Peccoud et al. 2010; Jousselin et al. 2010). A relationship with the feeding site rather than the host plant was also confirmed for Pterochloroides persicae (Lassaad et al. 2012).

A separate group (II) of Cupressobium are species not related to their microhabitat, which probably results from their ability to frequently change habitats depending on temperature. Such behavior is seen among $C$. tujafilina (which infests Thuja orientalis) and C. mordvilkoi (which only feeds on Juniperus communis) regularly throughout the year (Durak et al. 2008, and unpublished observations). This is also related to a very close symbiotic relationship of those species with ants, which often help them change habitats. However, the ability to infest various plants and easily switch hosts could have been the cause of speciation in phylogenesis of the Cinara belonging to both subgenera (Favret, Voegtlin 2004). This indicates their high flexibility facilitating fast spreading (Heie 1994; von Dohlen, Moran 2000; Normark 2000; Heie, Wegierek 2009). This leads to high morphological similarities between species, which often makes them very difficult to identify. Recently molecular analyses have been used to accurately classify those aphid species (Mujtar et al. 2009; Durak 2011; Chen et al. 2012). As with other aphid species, Cinara evolved mainly through adaptative evolution involving changes in bionomy, whereas morphological changes are a result of adjustment to infestation of new plant species (Heie, Wegierek 2009).

We suggest that Cinara (Cupressobium) are a monophyletic group of aphids. Phylogenetic relationships amongst Cupressobium do not result from the host plant, but from the site on the host plant or an ability to change the microhabitat. This suggests that the host switching is the main mode of speciation in this subgenus. We prove that host taxonomy cannot be applied to Cinara (Cupressobium) or Cinara (Cinara) (Favret, Voegtlin 2004). However, in both cases ecological features of a species are helpful in drawing phylogenetic conclusions. We recommend the EF1- $\alpha$ as an accurate marker gene for reconstructing phylogenetic relationships of lower-level taxa in aphids.

Acknowledgments This research was supported by grant number DN/ GrU/BR/2/2011 to Roma Durak.

Open Access This article is distributed under the terms of the Creative Commons Attribution License which permits any use, distribution, and reproduction in any medium, provided the original author(s) and the source are credited.

\section{References}

Blackman RL, Eastop VF (1994) Aphids on the World's Trees. An identification and Information Guide. CAB International and The Natural History Museum, London, 986 pp 
Burke GR, Normark BB, Favret C, Moran NA (2009) Evolution and diversity of facultative symbionts from the aphid subfamily Lachninae. Appl Environ Microbiol 75:5328-5335

Chen R, Jiang L-Y, Qiao G-X (2012) The Effectiveness of Three Regions in Mitochondrial Genome for Aphid DNA Barcoding: A Case in Lachininae. PLoS ONE 7(10):e46190. doi:10.1371/journal.pone. 0046190

Durak R (2011) Molecular and morphological identification of Cinara juniperi (De Geer) and C. mordvilkoi (Pašek) (Hemiptera, Aphidoidea). Bull Insectology 64:195-199

Durak R, Sadowska-Woda I, Machordom A, Borowiak-Sobkowiak B (2008) Biological and genetic studies of Polish populations of Cinara tujafilina. Bull Insectology 61:159-160

Eastop VF (1972) A taxonomic review of the species of Cinara Curtis occurring in Britain (Hemiptera: Aphididae). Bull Br Mus Nat Hist Entomol 27:103-186

Eastop VF (1986) Aphid-plant associations. Coevolution and Systematics (ed. by AR Stone and DL Hawksworth) Clarendon Press, Oxford, pp 35-54

Favret C, Voegtlin DJ (2004) Speciation by host-switching in pinyon Cinara (Insecta: Hemiptera: Aphididae). Mol Phylogenet Evol 32:139-151

Folmer O, Black M, Hoeh W, Lutz R, Vrijenhoek R (1994) DNA primers for amplification of mitochondrial cytochrome c oxidase subunit I from diverse metazoan invertebrates. Mol Mar Biol Biotechnol 3:294-299

Foottit RG (1992) The use of ordination methods to resolve problems of species discrimination in the genus Cinara Curtis (Homoptera: Aphidoidea: Lachnidae). In: Sorenson JT, Foottit RG (eds) Ordination in the Study of Morphology, Evolution and Systematics of Insects: Applications and Quantitative Genetic Rationals. Elsevier, Amsterdam, pp 193-221

Foottit RG, Maw HE, von Dohlen CD, Hebert PD (2008) Species identification of aphids (Insecta: Hemiptera: Aphididae) through DNA barcodes. Mol Ecol Resour 8(6):1189-1201

Gadek PA, Alpers DL, Heslewood MM, Quinn CJ (2000) Relationships within Cupressaceae sensu lato: a combined morphological and molecular approach. Am J Bot 87:1044-1057

Guldemond JA (1990) Evolutionary Genetics of the Aphid Cryptomyzus, with a Preliminary-Analysis of the Inheritance of Host Plant Preference, Reproductive-Performance and Host-Alternation. Entomologia Exp Appl 57(1):65-76

Hall TA (1999) BioEdit: a user-friendly biological sequence alignment editor and analysis program for Windows 95/98/NT. Nucleic Acids Symp Ser 41:95-98

Hall T (2007) BioEdit v7. Ibis Biosciences, Carlsbad

Hasegawa M, Kishino H, Yano TA (1985) Dating of the human-ape splitting by molecular clock of mitochondrial DNA. J Mol Evol 22:160-174

Heie OE (1994) Why are there so few aphid species in the temperate areas of the southern-hemisphere? Eur J Entomol 91:127-133

Heie OE, Wegierek P (2009) A classification of the Aphidomorpha (Hemiptera, Sternorrhyncha) under consideration of the fossil taxa. Redia XCI:67-77

Huelsenbeck JP, Ronquist F (2001) MRBAYES: Bayesian inference of phylogeny. Bioinformatics 17:754-755

Huelsenbeck JP, Ronquist F, Nielsen R, Bollback JP (2001) Bayesian inference of phylogeny and its impact on evolutionary biology. Science 294:2310-2314

Jousselin E, Genson G, Coeur d'acier A (2010) Evolutionary lability of a complex life cycle in the aphid genus Brachycaudus. BMC Evol Biol 10:295

Kim H, Lee S (2008) Molecular systematic of the genus Megoura (Hemiptera: Aphididae) using mitochondrial and nuclear DNA sequences. Mol Cells 25(4):510-522
Kusumi J, Tsumura Y, Yoshimaru H, Tachida H (2002) Molecular evolution of nuclear genes in Cupressacea, a group of conifer trees. Mol Biol Evol 19(5):736-747

Lassaad M, Martínez-Torres D, Monia BHL (2012) Two mitochondrial haplotypes in Pterochloroides persicae (Cholodkovsky) (Hemiptera: Aphididae: Lachninae) associated with different feeding sites. Insect Sci. doi:10.1111/j.1744-7917.2012.01547.x

Moran NA, Kaplan ME, Gelsey MJ, Murphy TG, Scholes EA (1999) Phylogenetics and evolution of the aphid genus Uroleucon based on mitochondrial and nuclear DNA sequences. Syst Entomol 24:85-93

Mujtar V, Covelli J, Delfino MA, Grau O (2009) Molecular identification of Cinara cupressi and Cinara tujafilina (Hemiptera, Aphididae). Environ Entomol 38(2):505-512

Normark BB (2000) Molecular systematics and evolution of the aphid family Lachnidae. Mol Phylogenet Evol 14:131-140

Nylander JA (2004) MrModeltest v2. Program distributed by the author. Evolutionary Biology Centre, Uppsala University

Ortiz-Rivas B, Martínez-Torres D (2010) Combination of molecular data support the existence of three main lineages in the phylogeny of aphids (Hemiptera: Aphididae) and the basal position of the subfamily Lachninae. Mol Phylogenet Evol 55(1):305-17

Page RDM (1996) TreeView: an application to dispaly phylogenetic trees on personal computers. Comput Appl Biosci 12: 357-358

Peccoud J, Simon JC, von Dohlen C, Acier A, Plantegenest M, Vanlerberghe-Masutti F, Jousselin E (2010) Evolutionary history of aphid-plant associations and their role in aphid diversification. C R Biologies 333(6-7):474-87

Rambaut A, Drummond AJ (2003-2009) Tracer: MCMC Trace Analysis Tool, v. 1.5.0. Available from: http://tree.bio.ed.ac.uk/software/ tracer/

Stern DL, Aoki S, Kurosu U (1997) Determining aphid taxonomic affinities and life cycles with molecular data: a case study of the tribe Cerataphidini (Hormaphididae: Aphidoidea: Hemiptera). Syst Entomol 22:81-96

Swofford DL (2002) PAUP: Phylogenetic Analysis Using Parsimony and Other Methods, Version 4.0 . Sinauer Associates, Sunderland, MA

Tamura K, Dudley J, Nei M, Kumar S (2007) MEGA4: Molecular Evolutionary Genetics Analysis (MEGA) software version 4.0. Mol Biol Evol 24:1596-1599

Thompson JD, Gibson TJ, Plewniak F, Jeanmougin F, Higgins DG (1997) The ClustalX windows interface: flexible strategies for multiple sequence alignment aided by quality analysis tools. Nucleic Acids Res 24:4876-4882

Voegtlin DJ, Bridges CA (1988) Catalog of the Cinara species of North America (Homoptera: Aphididae). Ill Nat Hist Surv Spec Publ 8

von Dohlen CD, Moran NA (2000) Molecular data support a rapid radiation of aphids in the Cretaceous and multiple origins of host alternation. Biol J Linn Soc 71:689-717

von Dohlen CD, Kurosu U, Aoki S (2002) Phylogenetics and evolution of the eastern Asian-eastern North American disjunct aphid tribe, Hormaphidini (Hemiptera: Aphididae). Mol Phylogenet Evol 23: 257-267

Watson GW, Voegtlin DJ, Murphy ST, Foottit RG (1999) Biogeography of the Cinara cupressi complex (Hemiptera: Aphididae) on Cupressaceae, with description of a pest species introduced into Africa. Bull Entomol Res 89:271-283

Winkler AS, Mitter C (2008) The phylogenetic dimension of insect-plant interactions: a review of the evidence. In: Tilmon KJ (ed) Specialization, Speciation, and Radiation. The Evolutionary Biology of Herbivorous Insects. University of California Press, Berkeley, pp 240-263 